\title{
Experimental study of surface finish of CFRP laminates under the influence of Magneto Rheological damping
}

\author{
Hakeemuddin Ahmed*, N.Seetharamaiah*, M.Manzoor Hussain** \\ *(Department of Mechanical Engineering, Muffakham Jah College of Engineering and Technology, \\ Hyderabad-500034 \\ **(Department of Mechanical Engineering, JawaharLal Nehru Technological University, Kukatpally \\ Hyderabad-500085
}

\begin{abstract}
Though the components made of composites are produced to their net shape yet they require machining to attain close tolerances and to facilitate their assembly. Carbon Fibre Reinforced Polymer (CFRP) composites are difficult to machine owing to the non-homogeneity of the constituent materials, fibre pullout, delamination and other problems. The variation of cutting forces is rather large due to the heterogeneous nature of these materials. This leads to tool vibrations and hence poor surface finish. The proper selection of the tool, process parameters and the ability to control the machining forces would result in better tolerances and improved surface finish. In this study, multiple slots are machined in CFRP laminate under different machining conditions of spindle speed, feed and depth of cut by using four fluted tungsten carbide end mill. A magneto- rheological (MR) device is utilized to suppress the tool vibrations and its effectiveness is studied by conducting the same set of experiments. It is observed that the MR fluid damping reduces the surface roughness by reducing the tool deflection.
\end{abstract}

Keywords: Carbon Fiber Reinforced Polymer (CFRP), End milling, Magneto-Rheological (MR) fluid damping, Tool deflection, Surface finish

\section{Introduction}

Nowadays Carbon Fiber Reinforced Polymer composites are widely used in aerospace, automotive and sports industry due to their excellent structural and thermal properties. These advanced materials have high specific strength and stiffness as these are light in weight. Generally the composite laminates/components are produced to their near net shape by various methods. As these components have to be assembled with other components in different ways, drilling and milling processes are most commonly performed. Sometimes the machining of these laminates becomes inevitable in order to obtain close dimensional tolerances and surface finish to meet the requirements for various applications. Whenever the laminated components are assembled together then the performance of the joint or the fit obtained depends critically on the quality of the mating machined surfaces. Milling is one of the most common machining operations performed in industries. Many researchers have studied the relationship between the cutting forces and the surface roughness during milling of CFRP. The machinability of the CFRP laminates has been studied under different machining conditions of speed, feed and depth of cut. Researchers have studied the dynamics of the end milling process in which instantaneous cutting position of the cutter was found to affect the metal cutting forces.

A.I.Azmi et al. [1] discussed the machinability of glass fiber reinforced composites (GFRP) during end milling by using Taguchi's method of design of experiments. The machinability of GFRP laminates was studied with respect to surface roughness, tool life and machining forces. Experiments were conducted under different cutting conditions by considering cutting speed, feed rate and depth of cut as factors at three levels according to the Taguchi design of experiments method. L. Sorrentino studied the milling of CFRP laminates and analysed the data using ANOVA technique. The author found a strong dependence of the thrust force and surface roughness on the machining parameters. Omer Arkan found that the damage factor in GFRP materials increased with an increase in cutting speed and feed rates while it decreased with increase in the number of flutes of the end mill. Karpat et al. [5] proposed a mechanistic force model for milling of CFRP by collecting cutting force data during slot milling of CFRP using polycrystalline diamond cutters. The model is shown to be capable of predicting cutting force during milling of multidirectional CFRP laminates. The relationship was represented with simple sine functions. Hocheng and Puw [7] investigated the cutting of unidirectional CFRP composites using a single square carbide insert. The researchers found that work piece fiber orientation had a significant effect on the formation of burrs and surface roughness. Good quality surface finish was obtained on the machined surface when the tool was fed along the fiber orientation. Paulo Davim et al.[6] evaluated the cutting parameters for milling of GFRP composite laminates with the aim to minimize the delamination factor and to maximize the surface finish. ANOVA technique was utilized to obtain the set of optimum cutting parameters for the two objectives. Rahman et al.[9] studied the machinability of CFRP composites with various cutting 
parameters with three types of cutting tool materials, namely uncoated carbides, ceramics and Cubic Boron nitride(CBN). The CFRP specimens had short (discontinuous) and long (continuous) fiber reinforcements. It was reported that the carbide tool performed better at low cutting speeds, whereas the performance of CBN tool was better than that of the others at high cutting speeds. Koplev et al.[8] contributed the first chip formation studies through orthogonal cutting of CFRP composites in the $0^{\circ}$ and $90^{\circ}$ fiber orientations. Devi Kalla et al. [5] developed a methodology for predicting the cutting forces by transforming specific cutting energies from orthogonal cutting to oblique cutting of CFRP composites. R.Madoliat, S.Hayati et al., [10] investigated the suppression of chatter of slender end mill via a frictional damper. It was shown that the friction damper improved the quality of surface finish during the end milling process. Palani Kumar et al., [11][12] evaluated the delamination factor in case of drilling and chatter in boring of GFRP composites.

In the present study, the smart behavior of the MR Fluid damping has been utilized to improve the surface finish by suppressing the deflections of the end mill during machining. Investigations are carried out by cutting multiple slots in CFRP laminates by considering all the combinations of different process parameters like speed, feed and depth of cut at three levels. The effect of the variation of these parameters on surface finish is investigated under the influence of MR damping.

\section{Materials And Tools}

Work piece material: $\mathrm{Bi}$ directional $\left(0^{0} / 90^{0}\right)$ CFRP laminates were fabricated by using woven carbon fibre cloth, epoxy resin (LY556) and hardener (LY551) to a size of 330mm x 170mm x $8 \mathrm{~mm}$ by hand layup process as shown in figure 1. There were seventeen layers in the laminate. These laminates were first tested for their tensile strength, flexural strength and hardness. All these characterisation tests were performed as per ASTM standards.

Cutting Tool: A four fluted tungsten carbide end mill (K20) of diameter $6 \mathrm{~mm}$ was selected for machining. It has equal shank and flute lengths of 50mm each as shown in Fig.2. Its helix, relief and clearance angles are $30^{\circ}$, $9^{0}$ and $16^{\circ}$ respectively. Forces during machining $\left(F_{m}\right)$ were measured in the $\mathrm{X}$ direction $\left(F_{x}-\right.$ feed force $), \mathrm{Y}$ direction $\left(F_{y}-\right.$ cutting force) and $\mathrm{Z}$ direction $\left(F_{z}-\right.$ thrust force) by means of a 3 -axis piezoelectric dynamometer. The resultant machining force $F_{m}$ is obtained by using the relationship $F_{m}=\sqrt{F_{x}^{2}+F_{y}^{2}+F_{z}^{2}}$.

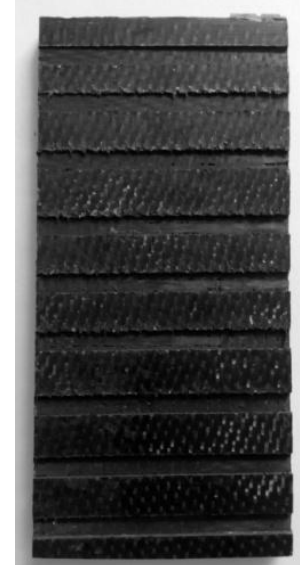

Fig.1. CFRP milled laminate

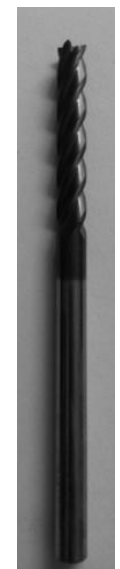

Fig.2. End mill

The end milling process involves the up milling and down milling cuts, the feed ' $\mathrm{f}$ ' along the feed direction which are shown in figure 3.

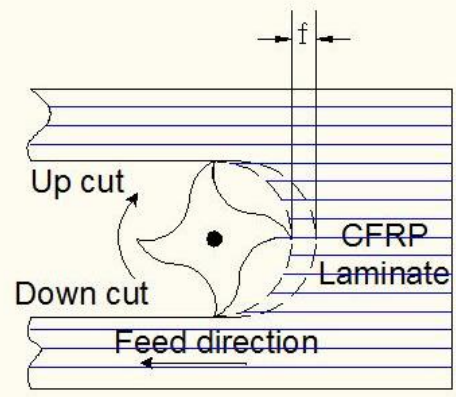

Fig.3. End Milling operation 
Magneto Rheological fluids: Magneto Rheological (MR) fluids are colloidal suspensions which exhibit large reversible changes in flow properties such as the apparent viscosity when subjected to sufficiently strong magnetic fields. They usually consist of micron-sized magnetizable solid particles suspended in a nonconducting liquid like mineral or silicone oil. MR fluid acts like a Bingham fluid and the variation of yield stress with respect to magnetic field intensity is non-linear.

MR fluid dampers: These devices enable active and semi-active vibration control systems with reaction times in the range of milliseconds and low power requirements. The damper consists of a cylinder filled with MR fluid and a piston over which a coil is wound. The gap between the cylinder and piston is kept at a constant value of $0.4 \mathrm{~mm}$. When the current is supplied to the coil, the suspended particles in the MR fluid form chains and hence there is an apparent increase in its viscosity. This helps in developing variable damping which is useful for many applications like vehicle suspension, earth quake mitigation, suppression of the vibrations during machining, prosthetics etc.

\section{Experimentation}

The experimentation was performed on a conventional vertical milling machine with the provision of attaching a magneto-rheological damper to the end mill. A Mitutoyo made dial gauge was used to test the runout of the machine spindle. The fabricated CFRP laminate was taken and a sample was prepared in accordance with the size of fixture available on the milling machine. The damper assembly comprised of clamps, T-shaped welded plate to support the damper and ball bearings of $6 \mathrm{~mm}$ diameter. The eye end of the damper carried the shank of end mill through the bearing. The MR damper with the associated fittings was attached to the machine as shown in figures 4. A vibration tester was employed as a diagnostic tool for preventive maintenance of the system involving the measurements of the RMS value of tool deflection. The magnetic probe was attached to the rotating end mill cutter covered by an assembly which is provided to prevent the abrasion of the contacting probe. A regulated current was supplied to the damper coil by using an ammeter.

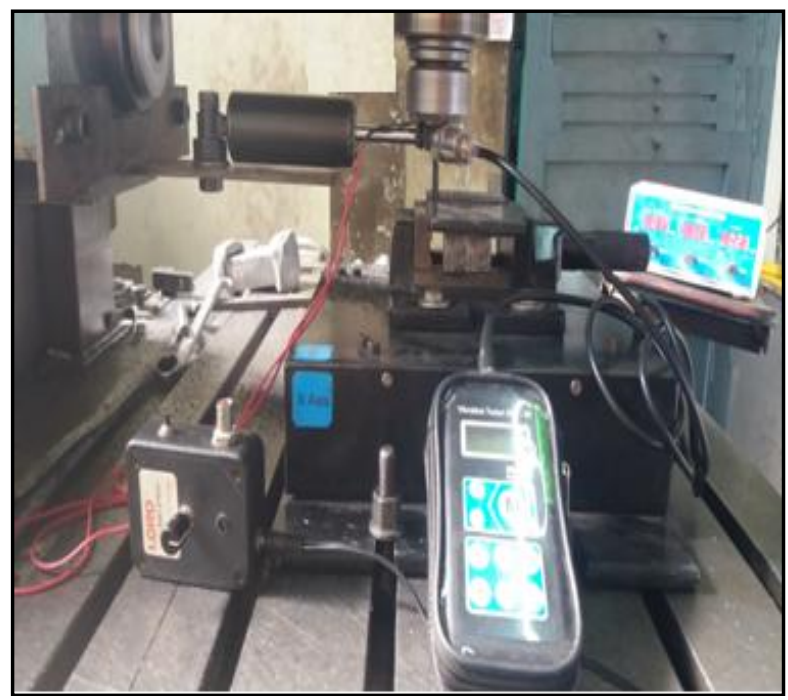

Fig.4. Experimental setup for milling

The experiments were carried out at three different spindle speeds of 315,400 and $500 \mathrm{rpm}$. The feeds considered were 32,40 and $50 \mathrm{~mm} / \mathrm{min}$ while the depths of cut were $0.3 \mathrm{~mm}, 0.4 \mathrm{~mm}$ and $0.5 \mathrm{~mm}$. As there are three factors involved at three levels, the total numbers of experiments is 27 as per the full factorial experimental design. The machining of CFRP laminates involves the interaction between the tool and its various phases i.e. carbon fibers and epoxy resin. Chatter arises due to the continuous variation in the cutting forces as a result of which the tool in contact with work piece is deflected. Multiple slots were produced as per the design of experiments without the use of MR damper as shown in figure 1. The same set of experiments was repeated under the influence of the magneto rheological damping. The coil current was incremented from $0.2 \mathrm{~A}$ to $2.0 \mathrm{~A}$ in order to increase the damping force. The tool deflections were found to be suppressed due to the current supplied. The coil current could not be increased beyond 2.0A as the properties of MR fluid reached the saturation value [13]. The surface roughness of the machined slots were evaluated and compared by using the Mitutoyo made Surface Roughness Tester sj-301 with a traversing length of $4 \mathrm{~mm}$ in both the cases. Five reading were taken at different locations as shown in Fig. 5 and their mean value was considered. 


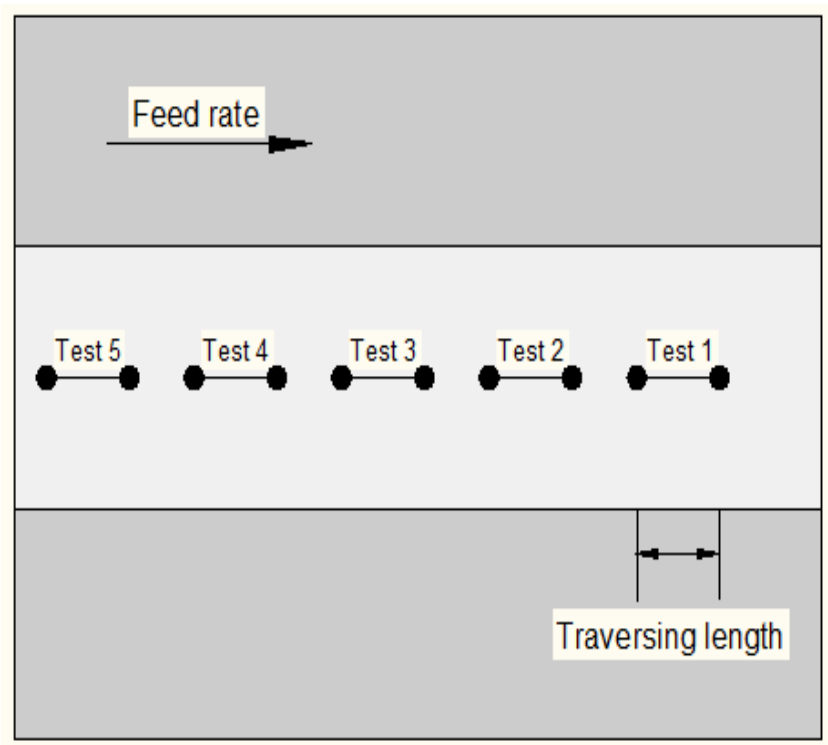

Fig.5. Evaluation of surface roughness

IV. Results And Discussions

When the damper is connected to the tool and the coil current is increased, the deflections are reduced gradually. The maximum effect of damper is observed at the saturation current of $2 \mathrm{~A}$.This behavior is observed when milling is carried out at different combinations of process parameters.

The behavior of the tool without (w/o) and with the damper assembly is shown in figure 6. It is observed that the tool deflection increases with an increase in feed rate for a given spindle speed and depth of cut. An increase in the feed rate causes an increase in cross section area of the undeformed chip thereby resulting in an increase in machining force and hence the tool deflection. Under the influence of MR damper at maximum current, it is observed that the tool deflection is reduced even at higher feed rates.

It is also observed that as depth of cut is increased, the tool deflection is also increased for a given feed and speed as shown in Fig. 7. The effect of increase in speed on the deflection was lesser when compared to that of feed and depth of cut. The tool deflection is reduced at higher speeds as the machining force is reduced. It is clearly evident from this figure that the tool deflections are reduced due to MR damping. When the machining is performed under the influence of MR damping, it is observed that the tool deflections are reduced up to $60 \%$ as the coil current is increased to a maximum of $2 \mathrm{~A}$ at $800 \mathrm{rpm}$.

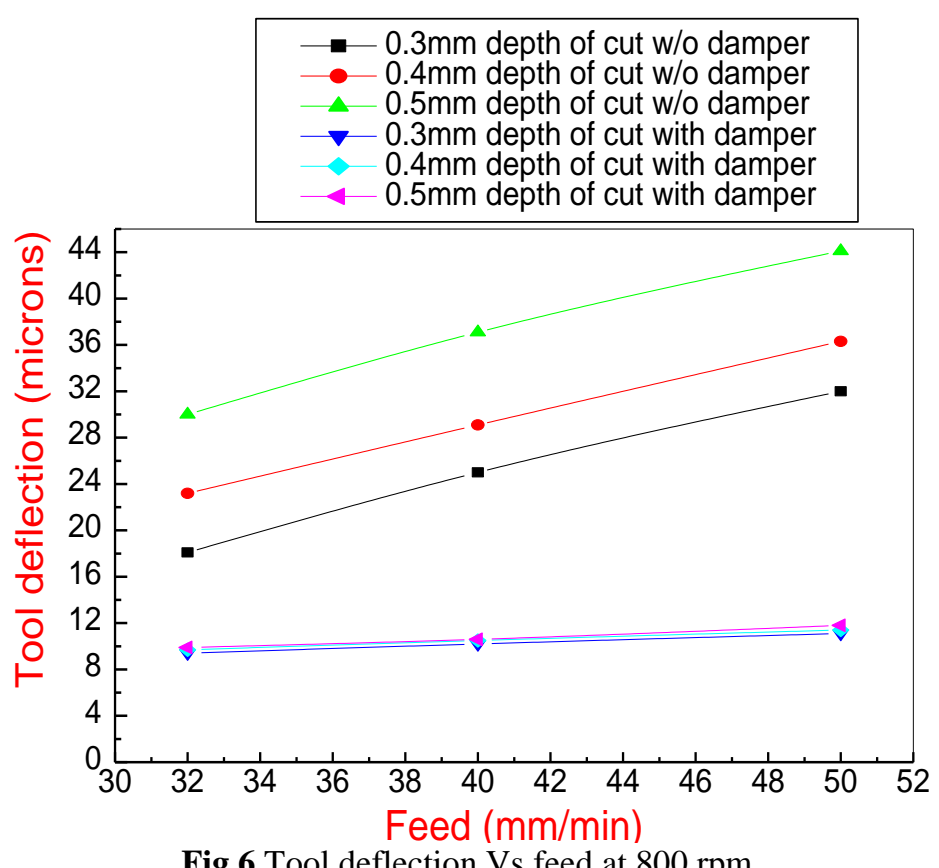

Fig.6.Tool deflection Vs feed at $800 \mathrm{rpm}$ 


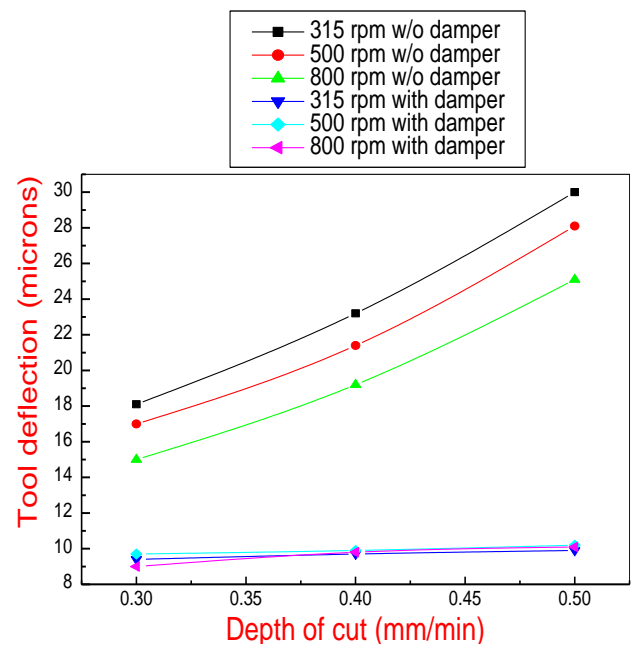

Fig.7. Tool deflection Vs depth of cut at feed $50 \mathrm{~mm} / \mathrm{min}$

The average surface roughness value obtained from the machined surface is found to increase with an increase in feed rate for a given spindle speed and depth of cut. At higher depth of cuts, the quality of the surface deteriorates as shown in Fig 8. The presence of MR damper improves the surface finish as observed in Fig. 8 and Fig. 9. The surface roughness is found to decrease with an increase in speed which is same as the general trend observed during machining of metals.

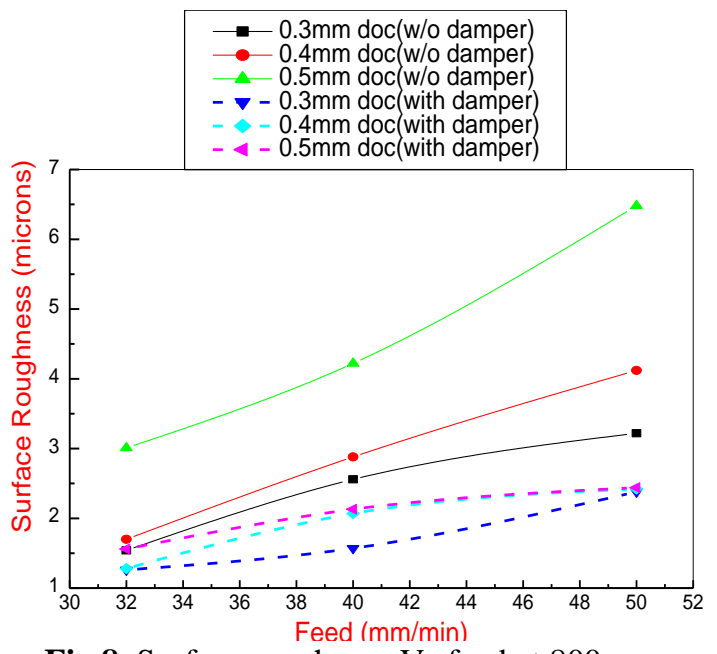

Fig.8. Surface roughness Vs feed at $800 \mathrm{rpm}$

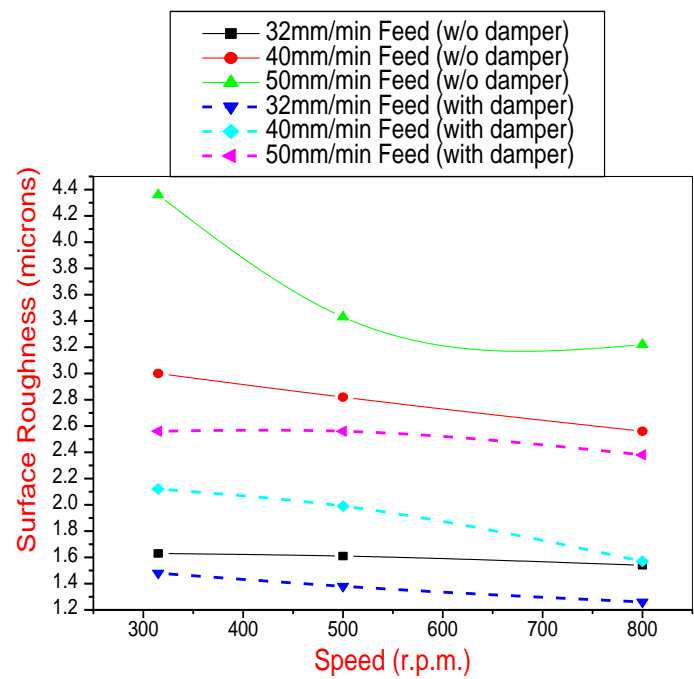

Fig.9. Surface roughness Vs speed at $0.3 \mathrm{~mm}$ depth of cut 
The minimum value of surface roughness can be minimized in the absence of MR damping to less than $4.5 \mu \mathrm{m}$ when the feed is maintained at around $46 \mathrm{~mm} / \mathrm{min}$ at $700 \mathrm{rpm}$ as shown in the contour plot of the response surface analysis, Fig.10. When machining is carried out under similar conditions of speed and feed at $0.4 \mathrm{~mm}$ depth of cut, the roughness are reduced to less than $2 \mu \mathrm{m}$ under the influence of damping as shown in Fig. 11 at the same speed.

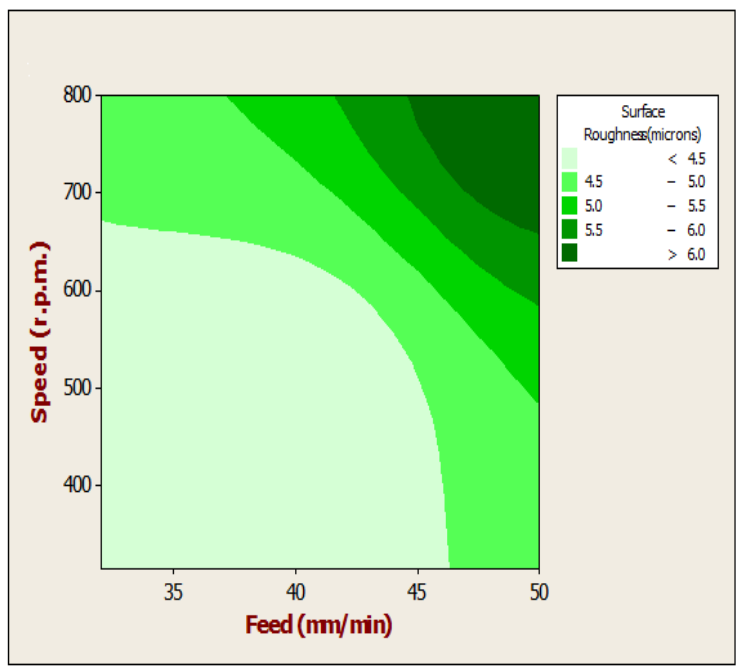

Fig.10. Contour plot of surface roughness without MR damper

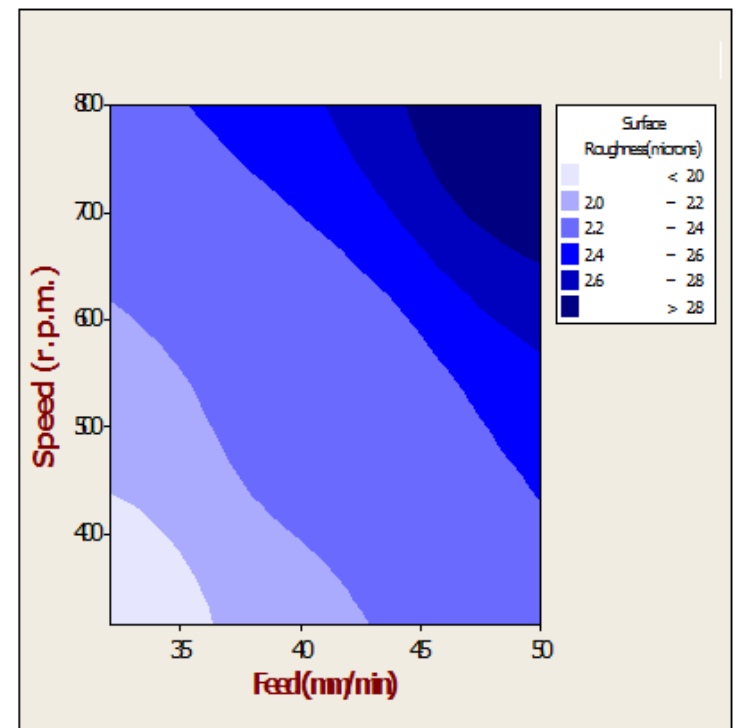

Fig.11. Contour plot of surface roughness with MR damper

\section{Conclusions}

The CFRP laminates were machined on a conventional vertical milling machine using tungsten carbide end mill by considering three factors viz. spindle speed, feed and depth of cut at three levels. The experimental results show that spindle speed and feed are the dominant factors that affected the tool deflection and the surface finish. When similar investigations are carried out under the influence of magneto-rheological damping, it is observed that the damping improved the quality of the surface finish at various values of the coil current. It is found that the MR damping reduced the surface roughness by $42 \%$ at $2 \mathrm{~A}$ current.

\section{References}

[1]. A.I. Azmi, R.J.T Lin, D. Bhattacharyya, Machinability study of glass fibre-reinforced polymer composites during end milling, Int. Journal of Advanced Manufacturing Technology (2013), pp 247-261

[2]. Altintas, Y. Shamoto, E., Lee, P., \& Budak, E. Analytical prediction of stability lobes in ball end milling. Journal of Manufacturing Science \& Engineering, Trans. ASME, 121(4), 1999, 586-592. 
[3]. B.F. Spencer Jr., S.J. Dyke, M.K. Sain and J.D. Carlson, Phenomenological Model for Magneto rheological Dampers, Journal of Engineering Mechanics, Vol.123, No.3, March 1997, pp 230-238

[4]. Devi Kalla, Jamal Sheikh-Ahmed, Janet Twomey, Prediction of cutting forces in helical end milling fiber reinforced polymers , International Journal of Machine Tools \& Manufacture (Elsevier) 50 (2010) pp 882-891.

[5]. Karpat, Y., O. Bahtiyar, and B. Değer, Mechanistic force modelling for milling of unidirectional carbon fiber reinforced polymer laminates. International Journal of Machine Tools and Manufacture. Vol 56, 2012, pp 79-93.

[6]. Davim, J.P, Reis, P. Damage and dimensional precision on milling carbon fiber-reinforced plastics using design of experiments, Journal of Materials Processing Technology 2005, pp 160-167.

[7]. H. Hocheng, C.C. Tsao, Comprehensive analysis of delamination in drilling of composite materials with various drill bits, Journal of Materials Processing Technology (Elsevier) 140 (2003) pp 335-339.

[8]. Koplev, A., A. Lystrup, and T. Vorm, The cutting process, chips, and cutting forces in machining CFRP Composites, Composites, 1983, 14(4)

[9]. Rahman, M., S. Ramakrishna, J.R.S. Prakash, and D.C.G. Tan, Machinability study of carbon fiber reinforced composite Journal of Materials Processing Technology, 1999, pp 292-297.

[10]. R. Madoliat, S. Hayati, A. Ghasemi Ghalebahman, Investigation of chatter suppression in slender end mill via a frictional damper, Scientia Iranica B (2011), 18 (5), pp 1069-1077.

[11]. Palanikumar, K.; Prakash, S. Shanmugam, K. Evaluation of delamination in drilling GFRP composites, Materials and Manufacturing Processes 2008, 23 (8), 858-864.

[12]. Sathya Narayan, L.Karuna Murty, K.Palani Kumar, Chatter suppression in boring operation using MR Damper, Journal of Materials and Manufacturing processes, 23(3-4) pp 329-335.

[13]. Engineering Note, Designing with MR Fluids, Lord Materials Division, 1999a. 